\title{
Transcatheter aortic valve implantation should be controlled and monitored by the medical profession
}

\author{
John E. Mayer, Jr, MD
}

On the basis of the accompanying case presentation of a 75-year-old widowed male nursing home resident with hemodynamically significant aortic stenosis, heart failure, angina, and a high surgical risk for a conventional aortic valve replacement, I support the proposition that the newly emerging transcatheter aortic valve implantation (TAVI) should be "rationed," or at least monitored and controlled. The Placement of AoRTic TraNscathetER Valve (PARTNER) trial assessed both the clinical outcomes and resource use results from this multicenter prospective, randomized trial of transcatheter aortic valve insertion in both patients at "high risk" for open heart aortic valve replacement and in surgically "inoperable" patients. The results of the trial indicated that in surgically inoperable patients receiving a transcatheter aortic valve compared with "medically treated" patients (most with balloon valvotomy alone), the 1-year mortality for patients undergoing TAVI was $30.7 \%$ versus $50.4 \%$ for "medically treated" patients. The stroke rate was $5 \%$ in the patients undergoing TAVI versus $1.1 \%$ in the medical group, and the major vascular complication rates were $16.2 \%$ versus $1.1 \%$ for TAVI and medically treated patients, respectively. ${ }^{1}$ The average total cost for the TAVI procedure itself was $\$ 46,238$, and the average total hospitalization cost for the admission at which TAVI was performed was $\$ 78,540$. The 1 -year average resource use after the TAVI admission was $\$ 29,352$ versus $\$ 52,724$ for those treated medically. The study showed that this therapy added on average 1.59 incremental life years at a cost of $\$ 50,212$ per added life year. The increment in quality-adjusted life years was 1.29 years at a cost of $\$ 61,889$ per added quality-adjusted life year. ${ }^{2}$ For this patient, my recommendation regarding the use of TAVI would rest on an assessment of his "frailty" and the presence of other comorbidities that would exert the dominant impact on his survival and quality of life. Being a widower and living in a nursing home alone do not represent sufficient comorbid conditions to preclude treatment.

\footnotetext{
From the Department of Cardiac Surgery, Children's Hospital Boston, and Harvard Medical School, Boston, Mass.

Read at the 91st Annual Meeting of The American Association for Thoracic Surgery, Philadelphia, Pennsylvania, May 7-11, 2011.

Received for publication Feb 3, 2012; accepted for publication Feb 5, 2012.

Address for reprints: John E. Mayer, Jr, MD, 300 Longwood Avenue, Boston, MA

02115 (E-mail: john.mayer@ cardio.chboston.org).

J Thorac Cardiovasc Surg 2012;143:771-3

$0022-5223 / \$ 36.00$

Copyright (c) 2012 by The American Association for Thoracic Surgery doi:10.1016/j.jtcvs.2012.02.001
}

However, I also conclude, on the basis of these data, that the diffusion of this technology should be carefully monitored and controlled by the medical profession. Some may argue that "monitoring and control" is a distinction without a difference from "rationing," but uncontrolled diffusion of new medical technology has been a major source of the current crisis in funding for medical care in the United States, ${ }^{3}$ with approximately $18 \%$ of the gross domestic product now devoted to health care. ${ }^{4}$ Given the growing elderly population in this country and the incidence of aortic valve sclerosis in this aging population, there is a significant likelihood that use of TAVI for all elderly patients with aortic valve disease could add significantly to the Medicare expenditures for cardiovascular disease.

$\mathrm{I}^{5}$ and others ${ }^{6,7}$ have argued that it is a responsibility of the medical profession to wisely allocate societal health care resources, but if TAVI results in improved 1-year survival, how could an ethical physician or surgeon, or an entire society "deny" a given individual patient access to this technology. Consideration of this dilemma reveals some fundamental conflicts both within the value structures of the medical profession and within the value structures of American society, which I will attempt to briefly describe. I will then offer my own thoughts on how to address some of these dilemmas.

As a starting point, it is important to distinguish between efficacy and effectiveness. Assessment of the efficacy and safety of medical devices is the province of the US Food and Drug Administration, which is tasked with determining whether a new device safely accomplishes the stated purpose of the device. This efficacy assessment is typically based on randomized clinical trials, such as the PARTNER trial, in carefully defined clinical populations. Effectiveness has been described as the outcome when this same device is deployed in the general population by the medical profession. The Food and Drug Administration does not have (or want) the legal mandate to regulate the practice of medicine, and thus the assessment of the effectiveness of a device has traditionally been the responsibility of the medical profession, although health services researchers increasingly have inserted themselves into this domain. The assessments of effectiveness involve the medical profession's obligations to society to self-regulate and to wisely allocate what is now becoming a scarce societal resource. I have argued that if the medical profession does not actively engage in this effectiveness assessment, then major resource allocation decisions will be made by those who 
do not take care of patients, and then the medical profession will have forfeited an important role and responsibility in American society. ${ }^{5,8}$ Krause, in Death of the Guilds, ${ }^{9}$ has pointed out that professions are granted privileges and prerogatives by a society only so long as society believes that the profession is acting in the society's interest and not in its own interest. In the context of other erosions of medicine's prerogatives and privileges that have occurred in recent years, including managed care constraints on diagnostic testing, medication use, and procedures, I believe that failure to address the effectiveness question by the profession, even if it means that professional income will suffer, will be a major mistake that will affect the ability of medicine to continue to function as a profession.

The overriding issue for this debate, however, is reconciliation of the 2 roles that physicians have: "healer of the sick" and "member of a profession." 5,6 These 2 roles have different historical roots and can potentially come into conflict, ${ }^{6}$ as in the case that served as the topic for this debate. Should a "healer of the sick" choose not to offer a potentially beneficial therapy to any patient? Should a member of a profession disregard the profession's responsibilities to the society that it serves by failing to self-regulate or to wisely allocate societal resources? If physicians and surgeons indiscriminately apply a new and expensive technology to any patient who might benefit, even if it will minimally prolong life or marginally reduce suffering, can the medical profession argue that there has been a wise use of society's health care dollar? Is there a means by which both of these responsibilities of the physician can be fulfilled? I submit that there is, and I believe that the solution to this dilemma must rest on a rigorous, controlled collection and analysis of data on both the clinical and the resource use outcomes for this transcatheter valve therapy. I submit that outcomes data have the greatest impact on physician practice, and these outcomes must include both clinical outcomes and resource use outcomes for the procedure itself and for at least several years after the procedure. I believe that this approach will, of necessity, require a controlled dissemination of this technology and linkage of clinical databases with administrative claims databases so that resource use over time can be assessed after device insertion. The presidents of the Society of Thoracic Surgeons and American College of Cardiology have published a joint position paper on transcatheter aortic valve technology in which these 2 professional societies advocate many elements of such an approach, including recommendations for a multidisciplinary team approach, specific requirements regarding facility resources, specific standardized protocols for management strategies, procedural performance, problem solving, and complication management, and the development of clinical databases and registries to evaluate practice patterns, treatment outcomes, and comparative effectiveness. ${ }^{10}$ The ASCERT (American College of Cardiology Foundation-The Society of Thoracic Surgeons Collaboration on the Comparative Effectiveness of Revascularization Strategies) study, in which I have been privileged to serve as a co-investigator, attempts to compare coronary bypass surgery with percutaneous coronary interventions and has used the Society of Thoracic Surgeons' Adult Cardiac Database and the American College of Cardiology interventional catheterization database with linkage of both databases to the Medicare claims database. This study has demonstrated that such database linkages can be accomplished and that long-term outcomes, including resource use, can be assessed through linkage of these datasets. We cannot ignore the simple notion that value equals quality divided by cost, and society must ultimately believe that the deployment of its resources is providing real value to its members and not just to the profession that provides the services.

It is my expectation that the information from an ongoing study of TAVI will provide direction to cardiologists and surgeons involved in this therapy to identify subgroups of patients for whom this therapy will provide little benefit and could result in significant harm, particularly neurologic injury. In addition, it will be critical that the patients be provided this information so that each may make his or her own decision. It is this type of rigorously collected and analyzed information that will provide a pathway through the dilemma posed by the coexisting roles of healer of the sick and member of a profession that must wisely allocate societal resources. I anticipate that the patient characteristics that will indicate little benefit from TAVI will be in the realm of noncardiac comorbidities and "frailty." There will always be differences of professional opinion in a given case, but the information on the outcomes and effectiveness of any therapy will enable physicians, surgeons, and patients to make the wisest choices both for the patient and for society to ensure that both patient and society recognize the value of the therapy.

It is for these reasons that I believe the diffusion of the transcatheter aortic valve replacement technology should be controlled and monitored by the profession. I believe that such a process is distinctly different from "rationing," particularly because rationing implies that the process would be carried out by an entity that is not directly involved in the interaction between patient and physician. If physicians, surgeons, and patients can rationally assess rigorously collected and analyzed information, then I am confident that the profession can be true to its responsibilities to both patients and society, and we in the profession can make the right recommendations to our patients regarding the application of this new technology. In so doing, we and our patients will be able to limit the application of this new technology to those who will best benefit by it and spare society, through its governmental representatives, from making ill-advised, blanket judgments about the wisdom of 
applying TAVI to individual patients or to an entire population.

\section{References}

1. Leon MB, Smith CR, Mack M, et al. Transcatheter aortic valve implantation for aortic stenosis in patients who cannot undergo surgery. N Engl J Med. 2010;363: 1597-607.

2. Reynolds MR, Magnuson EA, Wang K, et al. Lifetime cost effectiveness of transcatheter aortic valve replacement compared with standard care among inoperable patients with severe aortic stenosis: results from the PARTNER Trial (Cohort B). Circulation. 3 Feb 2012 [Epub ahead of print].

3. Hackbarth GD, Medicare Payment Advisory Commission. Report to the Congress: Medicare Payment Policy. March, 2011; executive summary, p xi. Available at http://www.medpac.gov/document_search.cfm. Accessed March 1, 2012.

4. Martin A, Lassman D, Whittle L, Catlin A. National Health Expenditure Accounts Team. Recession contributes to slowest annual rate of increase in health spending in five decades. Health Aff (Milwood). 2011;30:11-22.
5. Mayer JE. Is there a role for the medical profession in solving the problems of the American health care system? Ann Thorac Surg. 2009;87:1655-61.

6. Creuss RL, Creuss SR. The Osler Fellows Program: physicianship, professionalism, and medicine's social contract with society. Available at: www.docstop com/docs/4185673/The Osler Fellows Program. Accessed February 29, 2012.

7. ABIM Foundation, American Board of Internal Medicine, ACP-ASIM Foundation, American College of Physicians-American Society of Internal Medicine, European Federation of Internal Medicine. Medical professionalism in the new millennium: a physician charter. Ann Intern Med. 2002;136: 243-6.

8. Mayer JE. The American health care system and the role of the medical profession in solving its problems. Ann Thorac Surg. 2007;84:1432-4.

9. Krause EA. Chapter 2: the United States: capitalism dominant, professions pressured. In: Death of the Guilds. New Haven, CT: Yale University Press 1995:29-49.

10. Holmes DR, Mack MJ. Transcatheter valve therapy: a professional society overview from the American College of Cardiology Foundation and the Society of Thoracic Surgeons. Ann Thorac Surg. 2011;91:714-5. 